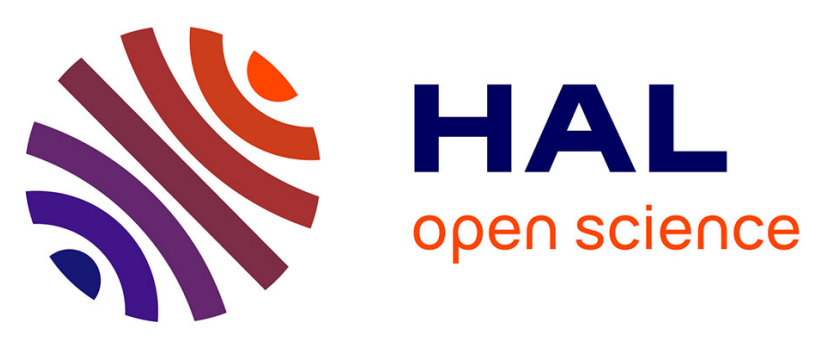

\title{
The inter-rater reliability of the Italian version of Aphasia Rapid Test (ART) for acute ischemic stroke
}

Mariangela Panebianco, Chiara Zavanone, Sophie Dupont, Patrizia Perrone, Antonino Pavone, Salvo Napolitano, Anne Leger, Yves Samson

\section{To cite this version:}

Mariangela Panebianco, Chiara Zavanone, Sophie Dupont, Patrizia Perrone, Antonino Pavone, et al.. The inter-rater reliability of the Italian version of Aphasia Rapid Test (ART) for acute ischemic stroke. Neurological Sciences, 2019, 40 (10), pp.2171-2174. 10.1007/s10072-019-03931-2 . hal-02353059

\section{HAL Id: hal-02353059 \\ https://hal.sorbonne-universite.fr/hal-02353059}

Submitted on 7 Nov 2019

HAL is a multi-disciplinary open access archive for the deposit and dissemination of scientific research documents, whether they are published or not. The documents may come from teaching and research institutions in France or abroad, or from public or private research centers.
L'archive ouverte pluridisciplinaire HAL, est destinée au dépôt et à la diffusion de documents scientifiques de niveau recherche, publiés ou non, émanant des établissements d'enseignement et de recherche français ou étrangers, des laboratoires publics ou privés. 


\section{Neurological Sciences \\ The inter-rater reliability of the Italian version of Aphasia Rapid Test (ART) for acute ischemic stroke \\ --Manuscript Draft--}

\begin{tabular}{|c|c|}
\hline Manuscript Number: & NEUS-D-19-00063R1 \\
\hline Full Title: & $\begin{array}{l}\text { The inter-rater reliability of the Italian version of Aphasia Rapid Test (ART) for acute } \\
\text { ischemic stroke }\end{array}$ \\
\hline Keywords: & reliability, Italian aphasia rapid test, stroke, French aphasia rapid test. \\
\hline \multicolumn{2}{|l|}{$\begin{array}{l}\text { Corresponding Author Secondary } \\
\text { Information: }\end{array}$} \\
\hline Corresponding Author's Institution: & Sorbonne Universite Faculte de Medecine Campus Pitie-Salpetriere \\
\hline \multicolumn{2}{|l|}{ First Author Secondary Information: } \\
\hline \multirow[t]{6}{*}{ Order of Authors: } & Mariangela Panebianco, Ph.D \\
\hline & Chiara Zavanone, M.D. \\
\hline & Sophie Dupont, Ph.D \\
\hline & Patrizia Perrone, M.D. \\
\hline & Antonino Pavone, M.D. \\
\hline & Salvo Napolitano, M.D. \\
\hline Abstract: & $\begin{array}{l}\text { Background } \\
\text { The Aphasia Rapid Test (ART) is a screening questionnaire used for examining } \\
\text { language in acute stroke patients. The ART was initially developed and validated in } \\
\text { French. The purpose of this study was to assess the inter-rater reliability of the Italian } \\
\text { ART. } \\
\text { Methods } \\
\text { The original version of the ART was translated into Italian. The inter-rater reliability } \\
\text { was assessed by two independent neurologists who were blind to each other's ratings } \\
\text { in } 52 \text { acute post-stroke patients. } \\
\text { Results } \\
\text { The } 52 \text { patients ( } 28 \text { men, } 24 \text { women; mean age } 73.73 \pm 28.99 \text { years) were included } \\
\text { within one week of stroke onset ( } 46 \text { ischemic, } 6 \text { haemorrhagic), as assessed by clinical } \\
\text { examination and confirmed by CT and/or MRI. The mean }( \pm S D) \text { ART value was } 9.38 \\
\text { ( } \pm 9.26) \text { for Rater } 1 \text { and } 9 \text { ( } \pm 9.31) \text { for Rater } 2 \text {. The inter-rater agreement was very good, } \\
\text { with a coefficient of concordance of } 0.99 \text { ( } 95 \% \text { CI: } 0.986-0.995 ; p<0.0001) \text { and a } \\
\text { weighted kappa of } 0.878 \text { and a quadratic weighted kappa of } 0.983 \text {. } \\
\text { Conclusions } \\
\text { This study showed that the cross-cultural adaptation of the French version of the ART } \\
\text { was successful in an Italian-speaking population. }\end{array}$ \\
\hline
\end{tabular}


Dear Editor,

We hereby submit a revised version of our manuscript: "The inter-rater reliability of the Italian version of Aphasia Rapid Test (ART) for acute ischemic stroke" for publication as a brief original study in Neurological Sciences.

We greatly appreciate the evaluation of our work by the Editorial Office and the reviewers, and the revised version carefully considers all comments.

Changes in the text are red-lined and a point-by-point response to each issue summarizes these changes.

Yours sincerely,

Chiara Zavanone (corresponding author)

\section{Reviewer 1}

General comment. This is a psychometric study that provides the Italian adaptation of Aphasia Rapid Test and evaluates its inter-rater reproducibility in 52 patients within one week of stroke onset. The topic sounds interesting and relevant to neurological practice.

Comment 1 . The concept of validity has not fully assessed in this study. The authors evaluate the inter-rater reproducibility among two raters, which is very important; however, they did not assess the agreement between the ART and others (already clinically accepted) language tasks that quantify the severity of initial post-stroke aphasia. A reliable measure is one that measures a construct consistently across time, individuals, and situations. A valid measure is one that measures what it is intended to measure. Inter-rater reproducibility is necessary, but not sufficient, for validity. To claim that the Italian ART is a valid and adequate measure of aphasia severity, the authors need to assess the construct validity, providing evidence of its convergent and divergent validity. Convergent validity is the level of agreement between a measure and other measures of the same construct. Discriminant validity is the lack of covariation between variables presumed to reflect different constructs (see Campbell \& Fiske, 1959). The convergent validity of the ART as a measure of language severity could be supported by the extent of its positive correlations with other existing aphasia severity scale. By contrast, discriminant validity of the ART could be support by the extent of its lack of correlation from non-language tasks. Therefore, I suggest to avoid the term validity throughout the paper and in the title, as well. Otherwise, the authors should properly provide: measures the construct of validity.

Reply: We agree with Reviewer 1 that our study didn't assess the validity but only the inter-rater reproducibility of the Italian ART.

So, as suggested by Reviewer 1, we changed the title of our article and we avoid the term validity in the text, as follows:

For the title: "The inter-rater reliability of the Italian version of Aphasia Rapid Test (ART) for acute ischemic stroke".

For the abstract, in the methods section: "The inter-rater reliability was assessed by two independent neurologists who were blind to each other's ratings in 52 acute poststroke patients".

For the abstract, in the conclusion section: "This study showed that the cross-cultural adaptation of the French version of the ART was successful in an Italian-speaking population."

For the text, in the introduction section: "The aim of this study was to translate the 
French ART into Italian to provide a simple and rapid method for the evaluation of language in Italian acute post-stroke patients".

For the text, in the method section:

"The final version of the questionnaire was administered to patients by two neurologists (MP: Rater 1 and SN: Rater 2) in an attempt to quantify the severity of aphasia within one week of stroke onset "

For the text, in the discussion section:

"Another limitation was the absence of the validation of the Italian version of the ART with other existing aphasia severity scales. However, in the Portuguese version the correlation between ART and the Lisbon Aphasia Examination Battery was strong $(r=$ $0.958, p<0.001$ ). The French version of the ART correlated with the severity score of the Boston Diagnostic Aphasia Examination [4] (see Table 1 in study of Rosso et al.)

[5]".

We added the following references:

4. Goodglass H, Kaplan E (1983) Boston Diagnostic Aphasia Examination (BDAE). 2nd ed. Lippincott Williams \& Wilkins, Philadelphia.

5. Rosso C, Vargas $P$, Valabregue $R$ et al. (2015) Aphasia severity in chronic stroke patients: a combined disconnection in the dorsal and ventral language pathways.

Neurorehabil Neural Repair 29:287-95.

For the text, in the conclusion section:

"In conclusion the ART appears to be a simple, rapid and reproducible languagefocused stroke scale to quantify the severity of initial aphasia and to monitor early changes in acute stroke patients."

Comment 2. How did the analysis of cultural characteristics has been performed? It is not clear to me what kind of psycholinguistic variables the authors considered in the selection of the Italian items to claim that "no inconsistencies were observed".

Reply:

We follow the recommendations according to Guillemin F [2]: "a distinction should be made between language, culture and country. A cultural setting do not necessary refer to one language nor to one country. The cross-cultural adaptation comprising of translation in standard language plus adjustment of cultural words, idioms and context, possibly involving the complete transformation of some items in order to capture the same concept".

In the methods section the sentence "the Italian version of the ART was analyzed for Italian cultural characteristics and no inconsistencies were observed", means that in the translation of the French ART into Italian, we didn't find substantially cultural differences. We also asked to an Italian professor (Costanza Zavanone, that we thank in the acknowledge session) to verify our translation and to search for mistakes and cultural inconsistencies.

The only discrepancy that she found between the two languages was for the term "macaron" translated in "maccherone", meaning pasta in Italian and not macaroon. This is not correct from a translation point of view but culturally it is closer to Italian habits; moreover it is phonologically similar to the French "macaron".

So we added this sentence in the text:

"We asked to an Italian professor to verify the translation. The only discrepancy that she found was for the term "macaron" translated in "maccherone", meaning pasta in Italian and not macaroon. This is not correct from a translation point of view but culturally it is closer to Italian habits; moreover it is phonologically similar to the French "macaron".

Reference:

2. Guillemin F (1995) Cross-cultural adaptation and validation of health status measures. Scand J Rheumatol 24:61-63

Reviewer 2:

This short paper reports the results of the validation study of a rapid and simple tool to assess language disorders in patients suffering from acute stroke. I believe the test could be useful to fill the gap between the rough "clinical impression" at bedside and the use of composite and time consuming batteries, often difficult to administer to patients in acute or immediate post-acute phases of stroke. I have no particular comments to do; however, a validation study should take into account the concurrent validity too. At this purpose, I would appreciate a short sentence included among 
limitations.

We agree with the Reviewer 2 since it was another limitation of our article as already underlined by Reviewer 1 (see comment 1). So we added this sentence in the discussion section of the text:

"Another limitation was the absence of the validation of the Italian version of the ART with other existing aphasia severity scales. However, in the Portuguese version the correlation between ART and the Lisbon Aphasia Examination Battery was strong ( $r=$ $0.958, p<0.001$ ). The French version of the ART correlated with the severity score of the Boston Diagnosticis Aphasia Examination [4] (see Table 1 in study of Rosso et al.) [5]".

We added the following references:

4. Goodglass H, Kaplan E (1983) Boston Diagnostic Aphasia Examination (BDAE). 2nd ed. Lippincott Williams \& Wilkins, Philadelphia.

5. Rosso C, Vargas P, Valabregue R et al. (2015) Aphasia severity in chronic stroke patients: a combined disconnection in the dorsal and ventral language pathways.

Neurorehabil Neural Repair 29:287-95. 
TITLE PAGE

The inter-rater reliability of the Italian version of Aphasia Rapid Test (ART) for acute ischemic stroke Authors

Mariangela Panebianco, M.D., Ph.D ${ }^{\mathrm{a}, \mathrm{b}}$; Chiara Zavanone, M.D. ; Sophie Dupont, M.D., Ph.D ${ }^{\mathrm{c}, \mathrm{d}}$; Patrizia Perrone, M.D. ; Antonino Pavone, M.D. a; Salvo Napolitano, M.D. a; Anne Leger, M.D.f; Yves Samson, M.D. d,f

a. Neurology Department, Garibaldi Hospital, Piazza Santa Maria di Gesù, 5, 95124 Catania CT, Italy

b. Department of Molecular and Clinical Pharmacology, Institute of Translational Medicine, University of Liverpool, United Kingdom

c. APHP, Neurological Rehabilitation Unit, Pitié-Salpêtrière Hospital, Sorbonne Universités, UPMC Univ Paris 06, 47-83 Boulevard de 1'Hôpital 75013 Paris, France

d. Inserm U 1127, CNRS UMR 7225, Sorbonne Universités, UPMC Univ Paris 06 UMR S 1127, Institut du Cerveau et de la Moelle épinière, ICM, F-75013, Paris, France

e. Neurology Department, Civile Hospital of Legnano, Via Candiani Cesare, 2, 20025 Legnano MI, Italy

f. APHP, Urgences Cérébro-Vasculaires, Pitié-Salpêtrière Hospital, Sorbonne Universités, UPMC Univ Paris 06, 47-83 Boulevard de l'Hôpital 75013 Paris, France

Corresponding author: Chiara Zavanone, Neurological Rehabilitation Unit, 47-83 Boulevard de 1'Hôpital 75013 Paris, France; Phone: +33 1 42160320; Fax: +33 1 42160303; E-mail: chiara.zavanone78@ gmail.com.

\section{E-mail addresses of each author: \\ m.panebianco@liverpool.ac.uk; \\ chiara.zavanone78@gmail.com; \\ sophie.dupont@aphp.fr; \\ patrizia.perrone@asst-ovestmi.it;}

hsepa@tin.it;

s.napolitano@ao-garibaldi.ct.it;

anne.leger@aphp.fr;

yves.samson@aphp.fr 
Key words: reliability, Italian aphasia rapid test, stroke, French aphasia rapid test.

\section{Word count: 1071}

Number of Figures: 1

Number of Tables: 1

\section{Conflict of interest statement}

The authors declare that they have no conflict of interest.

\section{Acknowledge}

Thank you to Costanza Zavanone, professor of Italian, for the collaboration in the translation of ART. 


\section{ABSTRACT (181 words)}

\section{Background}

The Aphasia Rapid Test (ART) is a screening questionnaire used for examining language in acute stroke patients. The ART was initially developed and validated in French. The purpose of this study was to assess the inter-rater reliability of the Italian ART.

\section{Methods}

The original version of the ART was translated into Italian. The inter-rater reliability was assessed by two independent neurologists who were blind to each other's ratings in 52 acute post-stroke patients.

Results

The 52 patients ( 28 men, 24 women; mean age $73.73 \pm 28.99$ years) were included within one week of stroke onset $(46$ ischemic, 6 haemorrhagic), as assessed by clinical examination and confirmed by CT and/or MRI. The mean ( \pm SD) ART value was $9.38( \pm 9.26)$ for Rater 1 and $9( \pm 9.31)$ for Rater 2 . The inter-rater agreement was very good, with a coefficient of concordance of 0.99 (95\% CI: $0.986-0.995 ; \mathrm{p}<0.0001)$ and a weighted kappa of 0.878 and a quadratic weighted kappa of 0.983 .

Conclusions

This study showed that the cross-cultural adaptation of the French version of the ART was successful in an Italianspeaking population. 


\section{Article}

\section{Introduction}

The Aphasia Rapid Test (ART) is a 26-points scale aimed to test language in post-stroke patients. It was initially developed in French at the Pitié-Salpêtrière Hospital in Paris and further validated by Azuar et al. [1]. This scale has multiple advantages: i) it is simple and rapid to realize in clinical setting, ii) it allows to rate aphasia severity at the bedside of acute post-stroke patients, iii) it may be used for the follow up and iv) it can be administered by any health care professional after brief training, without requiring any specific test material. The ART is based on the scoring of items that are commonly used in language's examination in acute post-stroke patients but the limit of this scale is the impossibility to discriminate between aphasia, apraxia of speech and dysarthria and therefore cannot be used as a diagnostic test or replace comprehensive language assessment of patients in speech therapy departments [1]. ART was designed to be easy to translate into any language and to be as little language-specific as possible and authors concluded that it needs to be tested and validated in other languages by independent studies in different countries. The crosscultural adaptation guidelines described by Guillemin et al. that are widely accepted were used for the translation and adaptation of questionnaires [2].

The aim of this study was to translate the French ART into Italian to provide a simple and rapid method for the evaluation of language in Italian acute post-stroke patients.

\section{Methods}

\section{Translation and cross-cultural adaptation process}

Two neurologists (CZ and MP), whose native language is Italian, made translation from the French version of ART into Italian. Italian version and French version of the ART are presented in Appendix 1.

The Italian version of the ART was analyzed for Italian cultural characteristics and no inconsistencies were observed. We asked to an Italian professor to verify the translation. The only discrepancy that she found was for the term "macaron" translated in "maccherone", meaning pasta in Italian and not macaroon. This is not correct from a translation point of view but culturally it is closer to Italian habits; moreover it is phonologically similar to the French "macaron".

\section{Patients}

52 consecutive patients, referred to the neurological department of Catania (Italy) between May 2015 and November 2015 for acute stroke, were recruited. These patients met the following criteria: admission to the stroke unit within $12 \mathrm{~h}$ of the onset of an acute stroke; left MCA infarct and/or haemorrhage confirmed by CT and/or MRI. All patients were 
right-handed, with Italian as their first language. Patients with impaired consciousness were excluded. Informed consent was not necessary, because aphasia assessing is part of standard care in stroke patients.

\section{Outcome scores}

The ART score ranges from 0 to 26 , with higher values indicating more severe impairment. The patient is successively asked to follow two simple orders (maximum 2 points), one more complex order (3 points), repeat three single words (6 points), repeat one sentence ( 2 points) and name three common objects (6 points). This is followed by a 1-min verbal semantic fluency task (4 points). The examiner additionally scores dysarthria ( 3 points) using the same scoring system as in the NIHSS. The final version of the questionnaire was administered to patients by two neurologists (MP: Rater 1 and SN: Rater 2) in an attempt to quantify the severity of aphasia within one week of stroke onset. The neurologists were blind to each other's ratings.

\section{Statistical analysis}

The inter-rater reliability of the ART was assessed by computing the coefficient of concordance. All statistical analyses were carried out using MedCalc for Windows (version 11.6.1.0; http://www.medcalc.be).

\section{Results}

We tested the inter-rater reproducibility of ART in 52 patients within one week of stroke onset.

The mean age $( \pm$ SD) of this population $(28$ men and 24 women) was $73.73( \pm 28.99)$ years. They had ischemic $(n=46)$ or hemorrhagic $(n=6)$ stroke. The mean $( \pm$ SD) ART value was $9.38( \pm 9.26)$ for Rater 1 and $9( \pm 9.31)$ for Rater 2 . Mean duration of ART administration was 169 seconds, including the 1-min fluency task. Table 1 shows the descriptive statistics of Italian population compared to the French one (see Azuar et al. [1]).

The inter-rater agreement was very good, with a coefficient of concordance of 0.99 (95\% CI: 0.986-0.995; p < 0.0001), a weighted kappa of 0.878 and a quadratic weighted kappa of 0.983 . The weighted kappa for ART's items ranged from 0.804 for the execution of simple orders to 0.968 for object naming.

The Bland-Altman plot of ART reproducibility (Fig.1) shows that ART is stable across all degrees of aphasia severity.

\section{Discussion}

The ART was designed in French language as a simple and reproducible language-stroke scale to quantify the initial aphasia severity and to monitor acute stroke patients.

Our study showed that the inter-rater agreement in Italian language was very good, with a coefficient of concordance of 0.99 (similarly to the French study). The time needed to fill-in the questionnaire, as well as the correlation between mean ART value Rater 1 and 2 obtained in Italian language, were very similar to those reported in the original French language [1]. 
Recently, ART was also validated in European Portuguese with an excellent inter-rater reliability (concordance coefficient between the two raters=0.95) [3] similar to the French and Italian inter-rater reliability. One possible explication of this excellent reliability is the lexical and grammatical similarities among the Romance languages (also called Neo-Latin languages) as French, Italian and European Portuguese. Another explication is the simplicity of the ART test.

Finally, ART has equivalent evaluation capacities in Italian population with acute stroke involvement to the original one. In this study, the limit consisted in the impossibility of evaluating the presence of a test-retest effect, but this was avoided in the French study that showed the lack of a test-retest effect of the ART scale. Another limitation was the absence of the validation of the Italian version of the ART with other existing aphasia severity scales. However, in the

Portuguese version the correlation between ART and the Lisbon Aphasia Examination Battery was strong $(r=-0.958, p$ $<0.001)$. The French version of the ART correlated with the severity score of the Boston Diagnostic Aphasia Examination [4] (see Table 1 in study of Rosso et al.) [5].

\section{Conclusions}

In conclusion the ART appears to be a simple, rapid and reproducible language-focused stroke scale to quantify the severity of initial aphasia and to monitor early changes in acute stroke patients.

Commented [ZC9]: Reviewer-1 comment 1 


\section{References}

1. Azuar C, Leger A, Arbizu C, Henry-Amar F, Chomel-Guillaume S, Samson Y (2013) The Aphasia Rapid Test: an NIHSS-like aphasia test. J Neurol 260:2110-2117.

2. Guillemin F (1995) Cross-cultural adaptation and validation of health status measures. Scand J Rheumatol 24:61-63.

3. Tábuas-Pereira M, Freitas S, Beato-Coelho J et al. (2018) Aphasia Rapid Test: Translation, Adaptation and Validation Studies for the Portuguese Population. Acta Med Port 31:265-271.

4. Goodglass H, Kaplan E (1983) Boston Diagnostic Aphasia Examination (BDAE). 2nd ed. Lippincott Williams \& Wilkins, Philadelphia.

5. Rosso C, Vargas P, Valabregue R et al. (2015) Aphasia severity in chronic stroke patients: a combined disconnection in the dorsal and ventral language pathways. Neurorehabil Neural Repair 29:287-95

\section{Figure Legends}

Fig.1 Bland-Altman plot of ART reproducibility

\section{Tables}

Table 1 Descriptive statistics of Italian and French population 


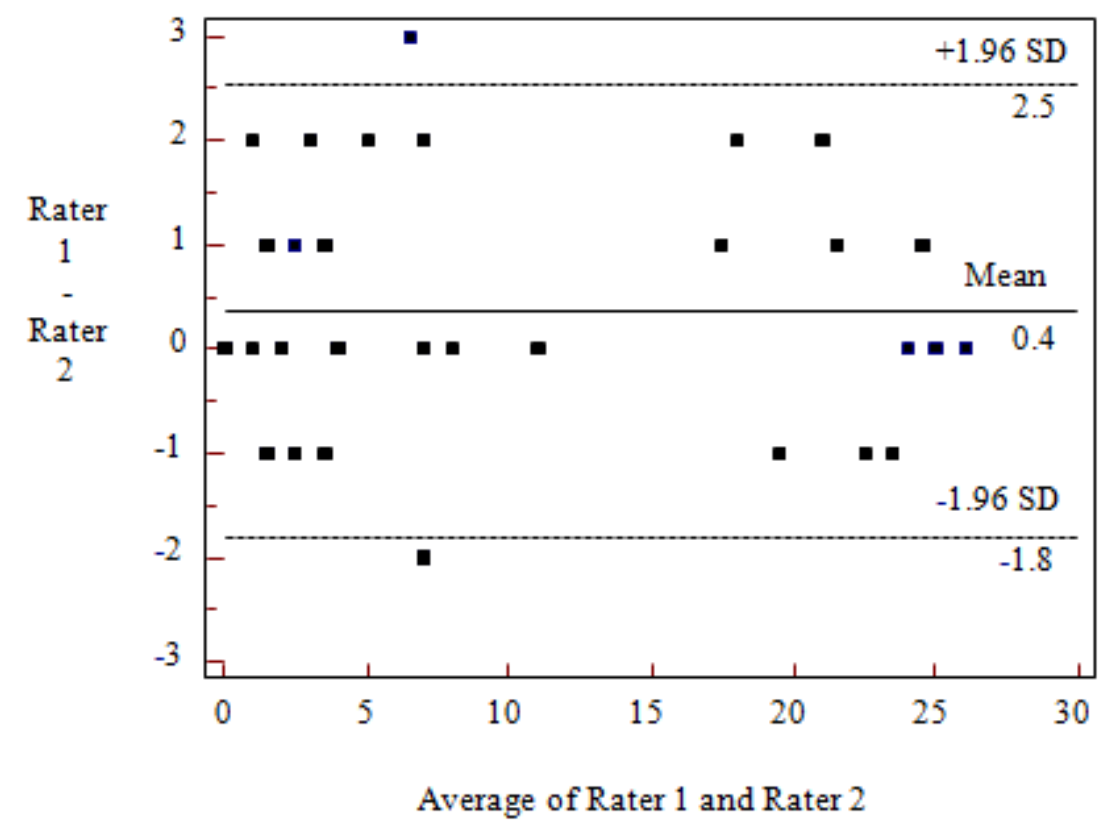

Fig.1 Bland-Altman plot of ART reproducibility 
Table 1 Descriptive statistics of Italian and French population

\begin{tabular}{ccc}
\hline Population & $\begin{array}{c}\text { Italian } \\
(\mathbf{n = 5 2})\end{array}$ & $\begin{array}{c}\text { French } \\
(\mathbf{n = 9 1})\end{array}$ \\
\hline M/F & $28 / 24$ & $52 / 39$ \\
\hline Mean age (years) & 73.73 & 63.96 \\
& $\left(S D^{* * \pm 28.99)}\right.$ & $\left(S D^{* * \pm} \pm 19.3\right)$ \\
\hline Ischemic/hemorrhagic & $46 / 6$ & $80 / 11$ \\
\hline Mean & 9.38 & 13.4 \\
ART* Rater 1 & $\left(S D^{* * \pm 9.26)}\right.$ & $\left(S D^{* * \pm 9.51)}\right.$ \\
\hline Mean ART* & 9 & 13.49 \\
Rater 2 & $\left(S D^{* * \pm} \pm 9.31\right)$ & $\left(S D^{* *} \pm 9.52\right)$ \\
\hline Median & 4 & 11 \\
ART* Rater 1 & $\left(I Q R^{* * *}: 2-19\right)$ & $\left(I Q R^{* * *}: 4.25-24\right)$ \\
\hline Median & 4 & 12 \\
ART* Rater 2 & $\left(I Q R^{* * *}: 2-18.5\right)$ & $\left(I Q R^{* * *}: 4.25-24\right)$ \\
\hline Mean duration & $169 \mathrm{~s}$ & $171 \mathrm{~s}$ \\
\hline administration (seconds) & & \\
\hline
\end{tabular}

*ART: aphasia rapid test; **SD: standard deviation; ***IQR: interquartile range 


\section{Chiara ZAVANONE}

Editor of " Neurological Sciences"

Hôpital Pitié-Salpêtrière, Paris, France

47-83 Bd de l'Hôpital

75013 Paris France

Tel: (33) 142162103

Fax: (33) 142161839

E-mail: chiara.zavanone@aphp.fr

Paris, $15 / 04 / 2019$

Dear Editor,

Please find enclosed our revised manuscript entitled "The inter-rater reliability of the Italian version of Aphasia Rapid Test (ART) for acute ischemic stroke" which we would like to submit to Neurological Sciences as brief original study.

Our study concerns the inter observer reproducibility of the Italian version of the Aphasia Rapid Test (ART) initially designed in French and already published in Journal of Neurology in 2013 by Azuar et al. This is a simple and rapid scale to test language at the acute stroke phase and we think it may be useful in the emergency setting. Therefore we translated it in Italian language and we hope you will be interested in our study and it will be published in your review.

I take full responsibility for the data, the analyses and interpretation, and the conduct of the research. I have full access to all of the data and I have the right to publish any and all data separate and apart from any sponsor.

The authors do not have any current or potential financial or other conflicts of interest related to the submitted manuscript. I certify that all co-authors of this article have seen and agree with the final version of the manuscript and accept responsibility for the data presented. This manuscript has not been published elsewhere and is not under consideration by another journal.

Yours, sincerely 
Dr. C. Zavanone 
Click here to access/download Supplemental Materials Appendix 1.docx 